\title{
Nonlinear Zonal Wind Response to ENSO in the CMIP5 Models: Roles of the Zonal and Meridional Shift of the ITCZ/SPCZ and the Simulated Climatological Precipitation*
}

\author{
KIT-YAN CHOI \\ Program in Atmospheric and Oceanic Sciences, Princeton University, Princeton, New Jersey \\ GABRIEL A. VECCHI \\ Program in Atmospheric and Oceanic Sciences, Princeton University, and NOAA/Geophysical Fluid Dynamics \\ Laboratory, Princeton, New Jersey \\ ANDREW T. WITTENBERG \\ NOAA/Geophysical Fluid Dynamics Laboratory, Princeton, New Jersey
}

(Manuscript received 19 March 2015, in final form 10 July 2015)

\begin{abstract}
The observed equatorial Pacific zonal wind response during El Niño tends to be stronger than during La Niña. Most global coupled climate models in phase 5 of CMIP (CMIP5) exhibit such nonlinearity, although weaker than observed. The wind response nonlinearity can be reproduced by driving a linear shallow water atmospheric model with a model's or the observed precipitation anomalies, which can be decomposed into two main components: the zonal and meridional redistribution of the climatological precipitation. Both redistributions contribute comparably to the total rainfall anomalies, whereas the zonal redistribution plays the dominant role in the zonal wind response. The meridional redistribution component plays an indirect role in the nonlinear wind response by limiting the zonal redistribution during La Niña and thus enhancing the nonlinearity in the wind response significantly. During La Niña, the poleward movement of the ITCZ/SPCZ reduces the equatorial zonal-mean precipitation available for the zonal redistribution and its resulting zonal wind response. Conversely, during El Niño, the equatorward movement of the ITCZ and SPCZ do not limit the zonal redistribution of precipitation. The linear equatorial zonal wind response to ENSO is found to have a significant linear correlation with the equatorial central Pacific climatological precipitation and SST among the CMIP5 models. However, no linear correlation is found between the nonlinear equatorial zonal wind response and the climatological precipitation.
\end{abstract}

\section{Introduction}

The El Niño-Southern Oscillation (ENSO) phenomenon is the world's dominant interannual climate signal. While the anomalous physical processes associated with

\footnotetext{
* Supplemental information related to this paper is available online at the Journals Online website: http://dx.doi.org/10.1175/ JCLI-D-15-0211.s1.

Corresponding author address: Kit-Yan Choi, Program in Atmospheric and Oceanic Sciences, Princeton University, Sayre Hall, 300 Forrestal Road, Princeton, NJ 08544.

E-mail:kityanc@princeton.edu
}

the warm (El Niño) and cold (La Niña) phases of the oscillation are, to the first order, mirror images of each other, multiple observational and model studies have noted the differences in amplitudes, patterns, and evolution between the two phases (Hoerling et al. 1997; Kessler 2002; Larkin and Harrison 2002; Ohba and Ueda 2009; Okumura and Deser 2010; Choi et al. 2013; Dommenget et al. 2013). These differences are often referred to as the nonlinearity or the asymmetry of ENSO, and they have significant impacts on regional climatic anomalies (Hoerling et al. 1997) and ENSO predictability (Dommenget et al. 2013). In this paper we focus on an atmospheric component of the nonlinearity-in particular, the equatorial Pacific zonal wind response to ENSO SST anomalies. 
Several studies have reproduced the nonlinear wind response by forcing an atmospheric model with symmetrical SST anomalies (i.e., SST anomalies that have the same spatial pattern and magnitude but with opposite signs; Hoerling et al. 1997; Kang and Kug 2002; Ohba and Ueda 2009). Features of the nonlinear zonal wind response that may influence the skewness and evolution of ENSO include 1) the zonal position of the equatorial wind response, 2) the meridional shift of the equatorial zonal wind response and its seasonality, and $3)$ the asymmetric amplitude of the equatorial zonal wind response (Harrison and Vecchi 1999; Kang and Kug 2002; Vecchi 2006; Ohba and Ueda 2009; Philip and van Oldenborgh 2009; Frauen and Dommenget 2010; McGregor et al. 2012). Within that rich spectrum of atmospheric nonlinearity, this study is focused on understanding the causes of the nonlinear amplitude of the zonal wind response.

There are two main sources for the pressure gradient anomalies that support the surface wind anomalies in the tropical Pacific: 1) elevated heating by deep convection (Gill 1980) and 2) changes in surface temperature (Lindzen and Nigam 1987). Chiang et al. (2001) showed that the zonal wind anomalies are largely explained by the elevated heating anomalies, which are associated with the precipitation anomalies. On the other hand, the eastward (westward) shift of the zonal wind anomalies during El Niño (La Niña) is also understood as being caused by the equatorial rainfall anomalies on an asymmetric climatological SST; the SST warming in the eastern equatorial Pacific causes equatorial rainfall to occur over the climatological cold tongue, whereas the SST cooling over the eastern equatorial Pacific displaces the rainfall onto the climatological warm pool. We hypothesize that the nonlinear precipitation response to the SST anomalies during ENSO is a crucial element in understanding the nonlinear zonal wind response. In this study we will examine if the nonlinear precipitation response to the SST anomalies is sufficient to explain the nonlinear zonal wind response.

While the zonal shift of equatorial convective regions during El Niño and La Niña is associated with the zonal movement of the upward branch of the Walker circulation, it is not obvious why the zonal wind anomaly during El Niño would necessarily be stronger than that during La Niña if indeed the nonlinearity in the zonal wind response comes mainly from the nonlinearity in the precipitation anomalies. In addition, the precipitation response to ENSO is not just about the zonal movement of convection; there is also an equatorward (poleward) movement of the intertropical convergence zone (ITCZ) and South Pacific convergence zone (SPCZ) during El Niño (La Niña) (Trenberth 1976; Folland et al. 2002; Chung et al. 2013; Chung and Power 2014).
Trenberth (1976) also noted the possible coupling between the SPCZ movement and the Walker circulation during ENSO. If one models the ITCZ and SPCZ as two Gaussian-shaped off-equatorial rainbands, an equatorward movement would lead to stronger precipitation anomalies over the equator than would a poleward movement. This study analyzes how much of the equatorial precipitation anomalies can be associated with this meridional movement and examines if the precipitation anomalies associated with the meridional movement of the ITCZ and SPCZ could be linked to the nonlinear zonal wind response to ENSO.

This paper is structured as follows. Section 2 describes the data being used and the methods of the analysis, including how the precipitation anomalies are decomposed into zonal and meridional redistribution of the climatological precipitation. Section 3 shows the components of the precipitation anomalies, the nonlinear zonal wind response to each of these precipitation components, and the effect of the biases in the climatological precipitation and the total precipitation response pattern. Finally, we summarize and discuss our results in section 4.

\section{Methods}

The nonlinear precipitation and equatorial zonal wind responses to ENSO are examined using a reanalysis of observations and coupled global climate model control experiments. A procedure to decompose the precipitation response into zonal and meridional redistribution and intensification components is designed and applied to models and observational estimates. After separating the precipitation anomalies into these three components, their individual impacts on the zonal wind response are explored by prescribing each as a heating anomaly in a shallow water model. In this section, we describe the data being used, how the ENSO composites and precipitation decomposition are computed, the shallow water model, and how the nonlinearity of wind response is quantified.

\section{a. Data}

In this study we focused on three physical quantities pertaining to ENSO: sea surface temperature in the tropical Pacific $\left(20^{\circ} \mathrm{S}-20^{\circ} \mathrm{N}, 100^{\circ} \mathrm{E}-100^{\circ} \mathrm{W}\right)$ along with its area average within the Niño-3.4 region $\left(5^{\circ} \mathrm{S}-5^{\circ} \mathrm{N}\right.$, $\left.170^{\circ}-120^{\circ} \mathrm{W}\right)$, surface zonal wind on the equator $\left(2^{\circ} \mathrm{S}-\right.$ $\left.2^{\circ} \mathrm{N}, 100^{\circ} \mathrm{E}-100^{\circ} \mathrm{W}\right)$, and the precipitation in the tropical Pacific basin $\left(20^{\circ} \mathrm{S}-20^{\circ} \mathrm{N}, 100^{\circ} \mathrm{E}-100^{\circ} \mathrm{W}\right)$. Observational reanalysis datasets are appropriate for this study because a consistent reconstruction of the three physical fields is required. Among the many reanalysis datasets, we used the Modern-Era Retrospective Analysis for 
Research and Applications (MERRA; Rienecker et al. 2011) as a reference for the observations. We also use the Global Precipitation Climatology Project, version 2.2, (GPCP; Adler et al. 2003) dataset for estimating the uncertainty in MERRA precipitation product. Other reanalysis datasets may be included in this study, but the differences among them are much smaller than those among the coupled models.

For the model data we used the preindustrial control experiments in phase 5 of the Coupled Model Intercomparison Project (CMIP5; Taylor et al. 2012). We have also utilized the free-run and flux-adjusted experiments of the Geophysical Fluid Dynamics Laboratory (GFDL) Climate Model, version 2.5 (CM2.5), forecastoriented low ocean resolution version (CM2.5-FLOR; Vecchi et al. 2014; Jia et al. 2015) for understanding the impact of the climatological precipitation on the zonal wind response. The CM2.5-FLOR model is built by coupling the atmosphere and land components of the GFDL CM2.5 (Delworth et al. 2012) to the ocean component of the low-resolution GFDL CM2.1 (Delworth et al. 2006). The atmosphere and land components have a horizontal resolution of about $50 \mathrm{~km}$, whereas the ocean component has a horizontal resolution of $10-25 \mathrm{~km}$.

Since the ENSO amplitude and the seasonal locking performance vary among models, we include in our composite analysis only the ENSO events whose Niño3.4 SST anomalies peak between 1.5 and $2.5 \mathrm{~K}$ from November to February. Among the models that have provided the required fields, two of them do not have both El Niño and La Niña simulated at the magnitude required and are therefore excluded from the composite analysis (Table 1).

\section{b. Shallow water model on a sphere}

The shallow water model has been used in many different contexts of meteorology and oceanography. With the $\beta$-plane approximation, it can be utilized as an anomaly model for understanding atmospheric and oceanic dynamics in the tropical regions (Matsuno 1966; Gill and Clarke 1974; Gill 1980). In this study, we follow the approach of Gill (1980).

The 1.5-layer, linear shallow water version of the GFDL spectral atmospheric dynamical core (Balaji 1998) is used to simulate the surface zonal wind anomalies corresponding to a given field of precipitation anomalies. In this configuration, the atmosphere is modeled by two layers of fluid of different densities. The thicknesses of the layers are assumed to be small compared to the characteristic horizontal scale of the motion for the hydrostatic balance assumption to hold. The top layer is assumed to be at a fixed height (i.e., a rigid lid approximation). The bottom layer is assumed to be stationary (i.e., the bottom pressure vanishes). The momentum equations are the same as in Matsuno (1966) but in spherical coordinates. And following Gill (1980), a heating anomaly term $Q$ is added to the model's thickness equation:

$$
\frac{D H}{D t}=-H \nabla \cdot \mathbf{u}-\varepsilon H+Q,
$$

where $H$ is the layer thickness, $\mathbf{u}$ is the horizontal velocity in the layer, and $\varepsilon$ is the damping rate. The intuitive understanding is that a positive heating anomaly would cause the upper layer to thicken, pushes the interface between the two layers downward, leads to a lower pressure, and drives wind convergence at the surface. The heating anomaly represents the latent heat anomaly caused by changes in the atmospheric convections. The wind response to a localized heating anomaly in the tropical regions resembles the results in Gill (1980).

This linear anomaly model is sometimes referred to as the Gill model, and it assumes that latent heating forcings drive low-level flows. This can be compared to the model by Lindzen and Nigam (1987), in which low-level flows are driven by boundary layer pressure gradients resulting from SST gradients and turbulent mixings. Nevertheless, the two models are formally analogous to each other; Neelin (1989) showed that the heating forcing in the thickness equation in the Gill model can be formulated as forcings in the momentum equations similar to those in the Lindzen and Nigam (1987) model. In addition, with the use of a more realistic model parameterization, Chiang et al. (2001) found that the elevated thermal heating anomalies are responsible for most of the zonal wind anomalies during an El Niño condition, whereas the surface temperature gradient contributes mostly to the meridional wind response. As our focus here is on the zonal wind response to ENSO, their results justify the Gill model approach in this context.

In this study the shallow water model is driven by precipitation anomalies, and the resulting lowertropospheric and surface zonal wind responses are the zonal wind anomalies we are interested in. But there are two more unknown parameters in setting up the shallow water model experiments. First of all, the heating forcings need to be converted from the precipitation anomalies. This is effectively asking for the vertical projection of the atmospheric heating anomalies onto the idealized profile assumed in the Gill model. Different models, including the real-world atmospheric heating, would have a different projection. Therefore, there is an unknown scaling factor in the heating anomalies for each model, and the scaling factor could also be different in El Niño and La Niña conditions. As the model is 
TABLE 1. CMIP5 models and modeling groups. Two models are marked as excluded from the composite analysis because of the lack of warm events with the required strength and seasonal locking. GFDL CM2.5-FLOR models are also included in this table. The rightmost column shows the number associated with each model in ascending order of the nonlinear equatorial zonal wind response. (Expansions of acronyms are available at http://www.ametsoc.org/PubsAcronymList.)

\begin{tabular}{|c|c|c|c|}
\hline Modeling center & Model & Length (yr) & Remark \\
\hline CSIRO & ACCESS1.0 & 250 & 23 \\
\hline Beijing Normal University (BNU) & BNU-ESM & 559 & 4 \\
\hline \multirow[t]{3}{*}{$\mathrm{CMCC}$} & CMCC-CESM & 277 & 12 \\
\hline & CMCC-CM & 330 & 6 \\
\hline & CMCC-CMS & 500 & 9 \\
\hline Centre National de Recherches Météorologiques (CNRM) & CNRM-CM5 & 850 & 20 \\
\hline CCCma & CanESM2 & 996 & 16 \\
\hline LASG-IAP & FGOALS-s2 & 501 & 29 \\
\hline \multirow[t]{5}{*}{ GFDL } & GFDL CM3 & 500 & 25 \\
\hline & GFDL-ESM2G & 500 & 32 \\
\hline & GFDL-ESM2M & 500 & 22 \\
\hline & CM2.5-FLOR & 300 & 17 \\
\hline & CM2.5-FLOR-FA & 300 & 28 \\
\hline \multirow[t]{4}{*}{ GISS } & GISS-E2-H & 531 & 21 \\
\hline & GISS-E2-H-CC & 251 & 18 \\
\hline & GISS-E2-R & 531 & 13 \\
\hline & GISS-E2-R-CC & 251 & 19 \\
\hline \multirow[t]{2}{*}{ Met Office Hadley Centre (MOHC) } & HadGEM2-CC & 240 & 2 \\
\hline & HadGEM2-ES & 337 & Excluded \\
\hline \multirow[t]{3}{*}{ IPSL } & IPSL-CM5A-LR & 1000 & 1 \\
\hline & IPSL-CM5A-MR & 300 & 8 \\
\hline & IPSL-CM5B-LR & 300 & 30 \\
\hline \multirow{3}{*}{$\begin{array}{l}\text { Model for Interdisciplinary Research on Climate } \\
\text { (MIROC) consortium }\end{array}$} & MIROC-ESM & 630 & 14 \\
\hline & MIROC-ESM-CHEM & 255 & Excluded \\
\hline & MIROC5 & 570 & 24 \\
\hline \multirow[t]{3}{*}{ MPI } & MPI-ESM-LR & 950 & 7 \\
\hline & MPI-ESM-MR & 1000 & 26 \\
\hline & MPI-ESM-P & 1156 & 11 \\
\hline Meteorological Research Institute (MRI) & MRI-CGCM3 & 500 & 31 \\
\hline \multirow[t]{2}{*}{ Norwegian Climate Centre (NCC) } & NorESM1-M & 501 & 15 \\
\hline & NorESM1-ME & 252 & 5 \\
\hline $\mathrm{BCC}$ & BCC_CSM1.1 & 500 & 3 \\
\hline Institute of Numerical Mathematics (INM) & INM-CM4.0 & 500 & 10 \\
\hline
\end{tabular}

linear, this scaling factor in the heating anomalies would be linearly reflected in the simulated surface wind anomalies. Under the assumption that the vertical projections of the atmospheric deep convections are (nearly) the same for the El Niño and La Niña conditions within one model, the results shown here comparing the relative difference between the wind response to El Niño and La Niña (see section 2d) should not be affected by the unknown scaling factor.

Another unknown parameter is the ratio between the Rayleigh damping (i.e., damping in the momentum equation) and the Newtonian cooling (i.e., damping in the thermodynamics or thickness equation) parameters. The meridional extent of the simulated surface wind anomalies depends on the ratio of these two parameters (Wu et al. 2001). We have checked that our results are insensitive to the ratios of the Rayleigh damping and Newtonian cooling rates ranging from 0.01 to 100 .
Since the model is linear, the wind response of the precipitation anomaly components can be added directly to recover the total wind response to the total precipitation anomalies.

\section{c. Decomposing the precipitation anomalies}

The total precipitation anomaly is decomposed into three components, each of which is attributable to 1) zonal redistribution of the climatological precipitation, 2) meridional redistribution of the climatological precipitation, and 3) intensity change. These components can be added linearly to recover the total precipitation anomaly exactly.

This decomposition is motivated from the observation that during ENSO the total change in the tropical Pacific $\left(20^{\circ} \mathrm{S}-20^{\circ} \mathrm{N}, 100^{\circ} \mathrm{E}-100^{\circ} \mathrm{W}\right)$ mean precipitation is about two orders of magnitude smaller than the anomaly local maxima, indicating that most of the anomaly is due to 
the redistribution of the climatological precipitation. And since the zonal wind response is the primary interest in this study, the zonal and meridional directions are the most relevant choice of axes for the decomposition of precipitation redistribution. Since the atmospheric response occurs fairly quickly relative to the monthly time scale, we assume that the redistribution in the two directions occurs concurrently.

To compute the anomaly corresponding to the zonal redistribution, the total precipitation during ENSO is divided by its zonal mean at each latitude and then multiplied by the zonal-mean precipitation in the climatology. In other words, the climatological precipitation is redistributed zonally to recover the zonal profile of the total precipitation. The anomaly $P_{x}^{\prime}$ is then calculated by subtracting the climatological precipitation from the normalized total precipitation:

$$
P_{x}^{\prime}=f_{x}\left(P_{\text {total }}, P_{\text {clim }}\right)=P_{\text {total }} \frac{\overline{P_{\text {clim }}} x}{P_{\text {total }}} x-P_{\text {clim }},
$$

where $P_{\text {total }}$ is the total precipitation field and $P_{\text {clim }}$ is the climatological precipitation from MERRA or models. The overbar represents taking the mean along a particular axis denoted in the superscript. Similarly, the anomaly $P_{y}^{\prime}$ associated with the meridional redistribution of precipitation is computed by normalizing the total precipitation using the meridional mean at different longitude:

$$
P_{y}^{\prime}=f_{y}\left(P_{\text {total }}, P_{\text {clim }}\right)=P_{\text {total }} \frac{{\overline{P_{\text {clim }}}}_{P_{\text {total }}}^{y}}{P_{\text {clim }}} .
$$

Both ${\overline{P_{\text {total }}}}^{x}$ and ${\overline{P_{\text {total }}}}^{y}$ are assumed to be positive definite (i.e., also nonzero).

When only one of the two directional redistributions is computed, the remaining precipitation anomalies not associated with that redistribution are large and also resemble the pattern of the other redistribution direction. This indicates that the redistribution of precipitation is significant in both directions, not just zonal or just meridional. On the other hand, when the zonal and meridional redistribution are performed sequentially, the corresponding anomalies depend on the order of operations. This highlights the fact that the zonal and meridional redistribution interact with each other by changing the mean along the other direction (i.e., the operations do not commute).

However, since we are assuming that the redistributions in the two directions occur concurrently, the decomposition should not depend on the relative sequence of the redistribution operations. To address this issue, the zonal and meridional operators [i.e., the $f_{x}$ and $f_{y}$ functions in Eqs. (1) and (2), respectively] are applied alternately and incrementally so that at each incremental step a fraction of the diagnosed redistribution anomaly is added to the total precipitation before the normalization on the other axis is applied. This iteration stops when the last anomaly increment is smaller than $1 \%$ of the accumulated anomaly. The anomaly increments are then aggregated into the zonal and meridional redistribution anomalies, respectively. The algorithm then becomes

$$
\begin{aligned}
& P_{x, 1}^{\prime}=f_{x}\left(P_{\text {total }}, P_{\text {clim }}\right) \\
& P_{y, 1}^{\prime}=f_{y}\left(P_{\text {total }}, P_{\text {clim }}+\frac{1}{2 n} P_{x, 1}^{\prime}\right) \\
& P_{x, 2}^{\prime}=f_{x}\left(P_{\text {total }}, P_{\text {clim }}+\frac{1}{2 n} P_{x, 1}^{\prime}+\frac{1}{n} P_{y, 1}^{\prime}\right) \\
& P_{y, 2}^{\prime}=f_{y}\left(P_{\text {total }}, P_{\text {clim }}+\frac{1}{2 n} P_{x, 1}^{\prime}+\frac{1}{n} P_{y, 1}^{\prime}+\frac{1}{n} P_{x, 2}^{\prime}\right) \\
& \vdots \\
& \quad \vdots \\
& P_{x, i}^{\prime}=f_{x}\left(P_{\text {total }}, P_{\text {clim }}+\frac{1}{2 n} P_{x, 1}^{\prime}+\sum_{j=2}^{i-1} \frac{1}{n} P_{x, j}^{\prime}+\sum_{j=1}^{i-1} \frac{1}{n} P_{y, j}^{\prime}\right) \\
& P_{y, i}^{\prime}=f_{y}\left(P_{\text {total }}, P_{\text {clim }}+\frac{1}{2 n} P_{x, 1}^{\prime}+\sum_{j=2}^{i} \frac{1}{n} P_{x, j}^{\prime}+\sum_{j=1}^{i-1} \frac{1}{n} P_{y, j}^{\prime}\right),
\end{aligned}
$$

where $P_{x, i}^{\prime}\left(P_{y, i}^{\prime}\right)$ is the zonal (meridional) redistribution anomaly computed at the $i$ th iteration. The concurrent zonal $P_{x}^{\prime}$ and meridional $P_{y}^{\prime}$ redistribution anomalies are redefined as

$$
\begin{aligned}
P_{x}^{\prime} & =\sum_{i=1}^{k} \frac{1}{n} P_{x, i}^{\prime} \quad \text { and } \\
P_{y}^{\prime} & =\sum_{i=1}^{k} \frac{1}{n} P_{y, i}^{\prime} .
\end{aligned}
$$

The iteration stops at the $k$ th iteration, when both $P_{x, k}^{\prime}$ and $P_{y, k}^{\prime}$ are smaller than $1 \%$ of $P_{x, k-1}^{\prime}$ and $P_{y, k-1}^{\prime}$, respectively. The residual component is then $P_{\text {total }}-P_{\text {clim }}-P_{x}^{\prime}-P_{y}^{\prime}$.

For the datasets used in this study, $n$ has to be larger than 4 for the results to be independent of the relative order of the zonal and meridional redistribution. And the results are insensitive to the choice of $n$ once $n$ is larger than 4. In this study, we used $n=50$. And $n$ and $k$ are not necessarily the same; the former is chosen such that the decomposition is independent of the order of the zonal and meridional redistributions, whereas the latter is not prescribed but simply dependent on the level of convergence. An alternative method that does 
(a)

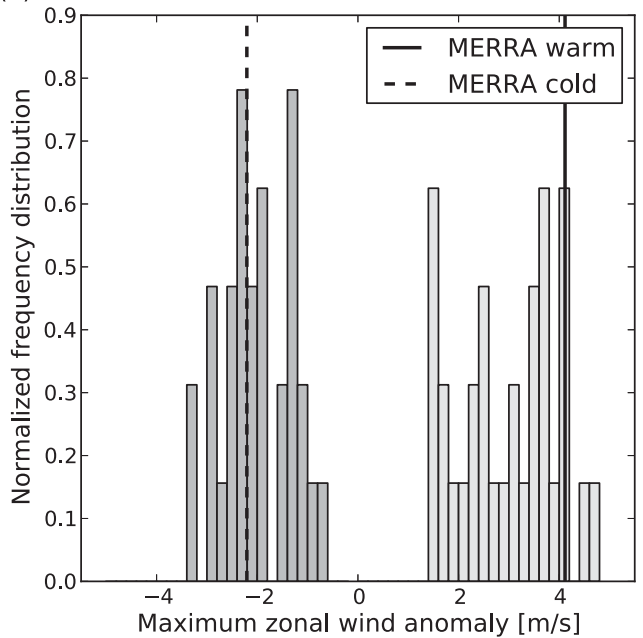

(b)

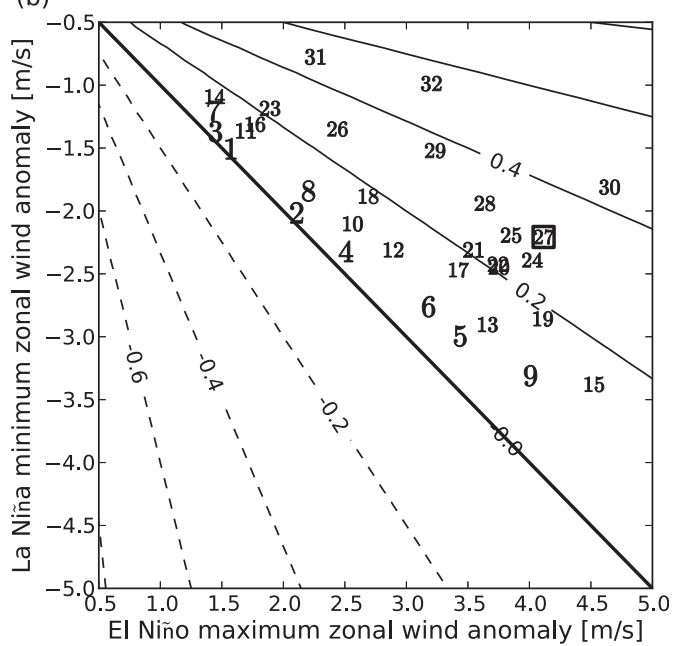

\begin{tabular}{|llllllllll|}
\hline 1 & IPSL-CM5A-LR & 8 & IPSL-CM5A-MR & 15 & NorESM1-M & 21 & GISS-E2-H & 27 & MERRA \\
2 & HadGEM2-CC & 9 & CMCC-CMS & 16 & CanESM2 & 22 & GFDL-ESM2M & 28 & CM2.5-FLOR-FA \\
3 & bCC-CSm1-1 & 10 & inmcm4 & 17 & CM2.5-FLOR & 23 & ACCESS1-0 & 29 & FGOALS-S2 \\
4 & BNU-ESM & 11 & MPI-ESM-P & 18 & GISS-E2-H-CC & 24 & MIROC5 & 30 & IPSL-CM5B-LR \\
5 & NorESM1-ME & 12 & CMCC-CESM & 19 & GISS-E2-R-CC & 25 & GFDL-CM3 & 31 & MRI-CGCM3 \\
6 & CMCC-CM & 13 & GISS-E2-R & 20 & CNRM-CM5 & 26 & MPI-ESM-MR & 32 & GFDL-ESM2G \\
7 & MPI-ESM-LR & 14 & MIROC-ESM & & & & & & \\
\hline
\end{tabular}

FIG. 1. (a) Normalized frequency distribution of the maximum composite zonal wind anomaly at 10-m height $\left(\mathrm{m} \mathrm{s}^{-1}\right.$ ) (averaged from $2^{\circ} \mathrm{S}$ to $2^{\circ} \mathrm{N}$, after $40^{\circ}$-longitude running mean within $100^{\circ} \mathrm{E}-100^{\circ} \mathrm{W}$ ) during El Niño (light gray) and La Niña (dark gray) in the CMIP5 models compared to MERRA. (b) Scatterplot of the maximum zonal wind anomaly during El Niño and La Niña. Contour lines (interval is 0.2) show the nonlinearity using Eq. (6). The square denotes MERRA.

not require iterations is presented in the appendix. The results presented in this study applied the iterative method, but the alternative method would give the same answers.

The advantage of this decomposition is that $P_{x}^{\prime}\left(P_{y}^{\prime}\right)$ has zero zonal (meridional) mean and zero area mean over the tropical Pacific. The solution of the decomposition is unique because of the assumption that there is no preferred order of the zonal and meridional redistributions (i.e., the two redistributions occur simultaneously). A proof of this uniqueness is presented in the appendix. Examples of idealized precipitation redistribution and the corresponding redistribution components are presented in the supplemental material.

When investigating the indirect role of the meridional redistribution of precipitation on the nonlinear wind response, the meridional redistribution anomalies are discarded and the resulting zonal redistribution precipitation anomaly is termed the nonconcurrent zonal redistribution anomaly:

$$
\text { nonconcurrent } P_{x}^{\prime}=f_{x}\left(P_{\text {total }}, P_{\text {clim }}\right) \text {, }
$$

as defined in Eq. (1), which does not involve iterations.

\section{d. Defining nonlinearity}

The nonlinearity in the zonal wind response is quantified by the relative difference in the response between El Niño and La Niña (as in Choi et al. 2013):

$$
\text { nonlinearity }=\frac{\text { El Niño }+ \text { La Niña }}{\text { El Niño }- \text { La Niña }} \text {. }
$$

When the nonlinearity of equatorial Pacific zonal wind response is sought after, the magnitude of the response refers to the maximum anomaly within $2^{\circ} \mathrm{S}-2^{\circ} \mathrm{N}$, $100^{\circ} \mathrm{E}-100^{\circ} \mathrm{W}$, after a $40^{\circ}$-longitude running mean. We use the maximum anomaly in order to account for the fact that the zonal wind anomaly is shifted eastward (westward) during El Niño (La Niña).

\section{Results}

\section{a. Nonlinear zonal wind response in models and observations}

The nonlinearity in the zonal wind response to ENSO in the observations and the CMIP5 models is shown in Fig. 1. MERRA shows a stronger equatorial zonal wind response to El Niño than La Niña. The CMIP5 models generally agree with this positive nonlinearity [Eq. (6)]. 


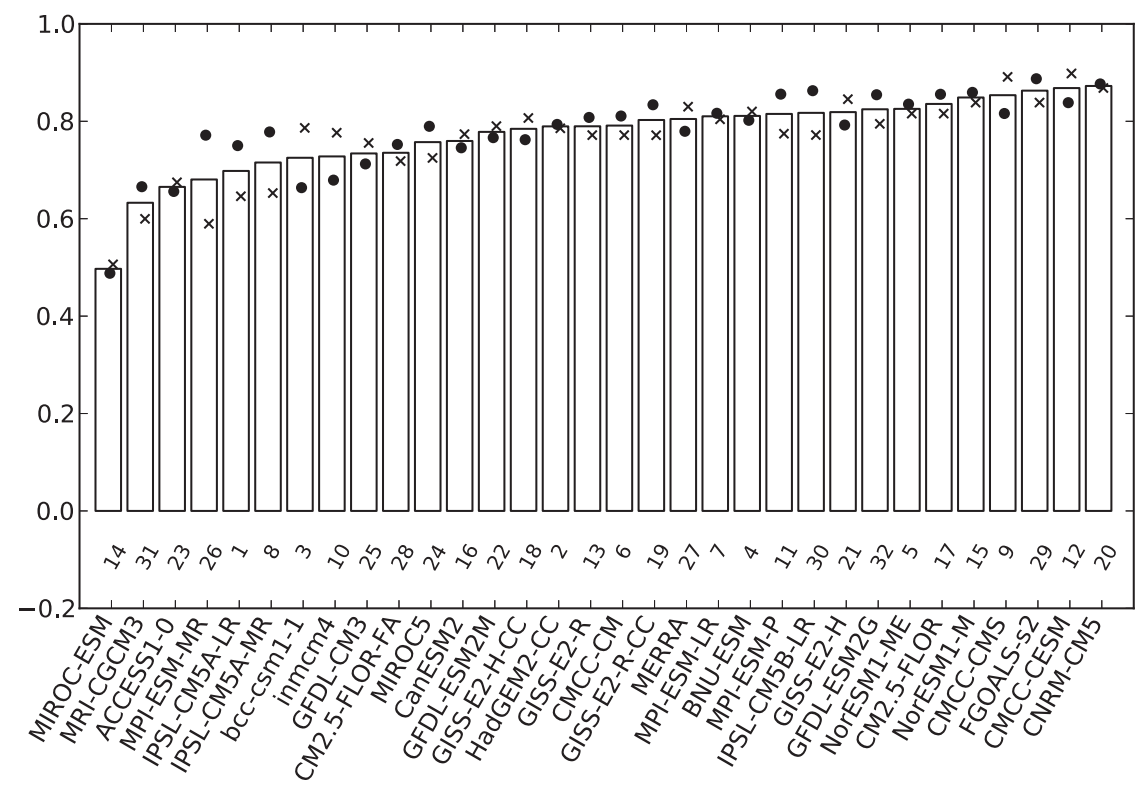

FIG. 2. Spatial correlation (within $20^{\circ} \mathrm{S}-20^{\circ} \mathrm{N}, 100^{\circ} \mathrm{E}-100^{\circ} \mathrm{W}$ ) between the zonal wind anomalies simulated by the shallow water model and the CMIP5 models. Circles (crosses) denote the correlations for warm (cold) events. Numbers below bars correspond to those in Fig. 1.

While models' response to La Niña tends to cluster around observed, El Niño zonal wind response tends to be underestimated so that the overall nonlinearity is weaker than observed. This agrees with Zhang and Sun (2014), who found a common underestimate of the ENSO asymmetry and a weaker precipitation response to El Niño in the eastern equatorial Pacific in the CMIP5 models. Here we refine their findings by keeping the amplitudes of the El Niño and La Niña SST anomalies fixed across observation and model composites, therefore eliminating the possible bias due to an increasing nonlinearity with the amplitude of ENSO events.

We test the hypothesis that the nonlinearity in the precipitation anomalies determines the nonlinearity in the zonal wind response. The models' precipitation anomalies are used to drive the shallow water model as heating anomalies. It is found that the spatial structures (Fig. 2) and the intermodel spread in the strength of the coupled models' zonal wind response (Fig. 3) are fairly similar to those simulated in the shallow water model. Furthermore, the coupled models' nonlinear wind response is also reproduced with a correlation coefficient of about 0.7 (confidence level above 99.9\%; Fig. 4). As the shallow water model is linear, this result supports the idea that the nonlinearity in the zonal wind response is largely due to the nonlinearity in the precipitation response, although the coupled models generally show less nonlinearity than expected from the linear shallow water response to the observed precipitation anomalies.
Outliers in Fig. 4 may be because the zonal wind response in these few coupled models are not represented well by the shallow water model for both or either of the El Niño and La Niña situations (Fig. 2). In addition, the shallow water model experiments that show negative nonlinear wind response for CMCC-CM, HadGEM2CC, and BCC_CSM1.1 disagree with the coupled model response. This discrepancy is likely due to the small number of events in the composites and the small nonlinearity in these models and thus a small signal-to-noise ratio. In fact, when the composites were computed for weaker events (absolute Niño-3.4 index being 0.5-1.5 K; not shown) in these models, the number of events increases significantly and the corresponding nonlinear wind response to the precipitation anomalies becomes positive. As the strength of the nonlinearity increases with the strength of ENSO events (Hoerling et al. 2001; Chung et al. 2013) and most CMIP5 models underestimate the observed nonlinearity, there is a tradeoff between the signal-to-noise ratio and the number of events while choosing whether to use weaker events (weaker nonlinearity, more events) or stronger events (stronger nonlinearity, fewer events) for the composites. This is also true for observational datasets.

\section{b. Nonlinear zonal wind response explained by each precipitation anomaly component}

Since the nonlinearity in the zonal wind response is mainly due to the nonlinearity in the precipitation 


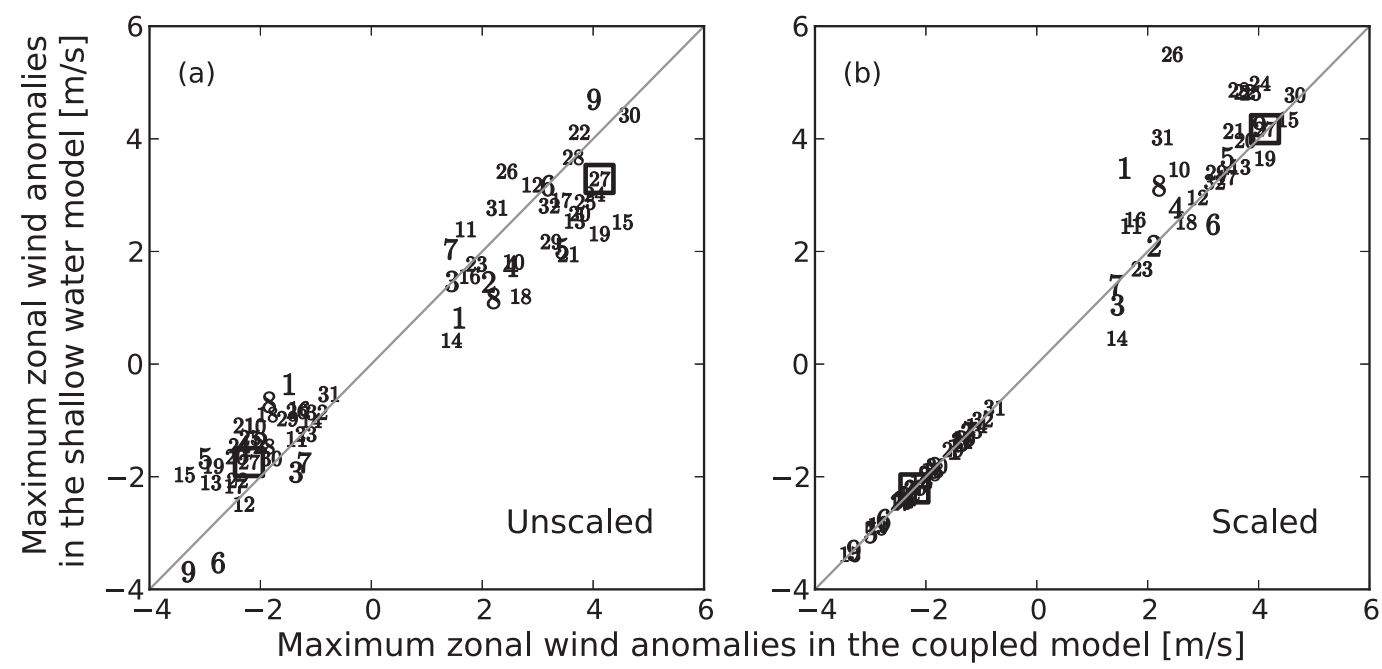

FIG. 3. (a),(b) Scatterplots for the equatorial Pacific zonal wind response during ENSO in the coupled models and in the shallow water model with the coupled model precipitation anomalies prescribed as heating. The straight line presents the reference for a one-to-one mapping. In (b), the La Niña surface zonal wind response in the shallow water model is scaled to match the corresponding coupled model. The same scaling factor is then applied to the surface zonal wind response to El Niño. Such scaling is not applied elsewhere in the paper and does not matter in the nonlinear wind response, which is nondimensional (section $2 \mathrm{~d}$ ). See section $2 \mathrm{~b}$ for a description of the scaling factor.

anomalies, we investigate how the precipitation anomalies achieve such a nonlinear zonal wind response and, in particular, the roles of the zonal and meridional redistribution of the precipitation anomalies in causing the nonlinearity. Before diagnosing the zonal wind response to each of these precipitation anomaly components, we analyze their spatial features and quantitative contributions to the total precipitation anomalies.

The meridional redistribution of precipitation is characterized by an equatorward (poleward) movement of the ITCZ/SPCZ during El Niño (La Niña), whereas the zonal redistribution represents the eastward (westward) shift of precipitation during El Niño (La Niña) (Fig. 5). Both components have comparable amplitudes but very different spatial structures, although they are not entirely orthogonal (spatial correlations are about 0.0-0.4). They are also similar to the leading components diagnosed from the principal component analysis that have strictly zero spatial correlation but nonzero zonal and meridional means [not shown; similar analysis using a satellite dataset can be found in Haddad et al. (2004)]. The sum of the zonal and meridional redistributions recover almost all of the total precipitation anomalies; the residual precipitation anomalies not associated with these redistributions are about two orders of magnitude smaller (Fig. 6) and are therefore neglected for most of the following analysis.

The relative contribution of each of these components to the nonlinear wind response was examined by forcing the shallow water model with the corresponding heating anomalies. We found that although the zonal and meridional redistribution anomalies have comparable contribution to the overall precipitation anomalies, the zonal wind response estimated from the shallow water

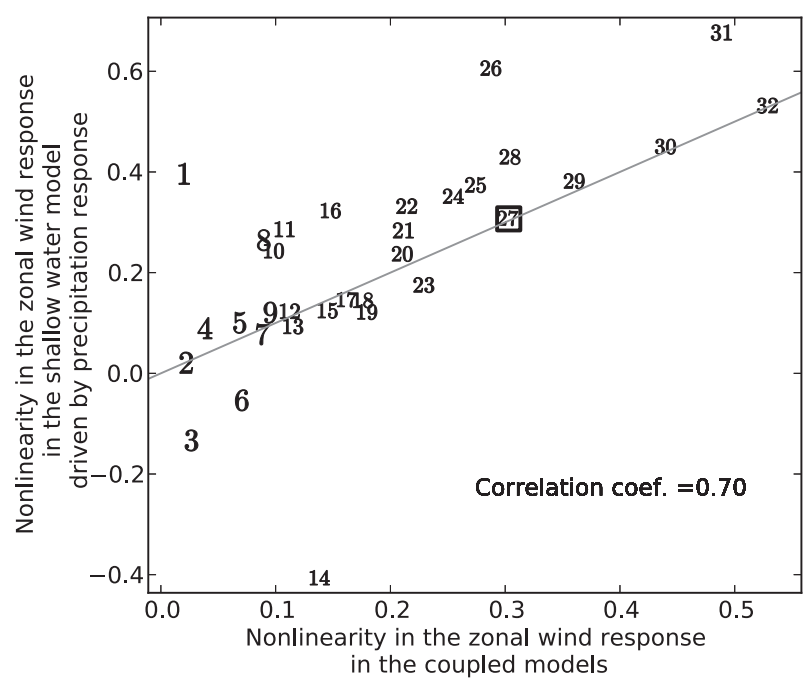

FIG. 4. Coupled models nonlinear wind response to ENSO events compared to the nonlinear wind response in the shallow water model with the corresponding precipitation anomalies prescribed as heating. The straight line presents the reference for a one-to-one mapping. Points are sorted according to the nonlinear zonal wind response in the coupled models and so the numbered markers are the same as those in Fig. 1. 
(a)
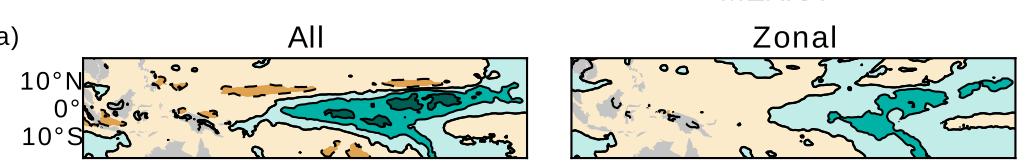

a
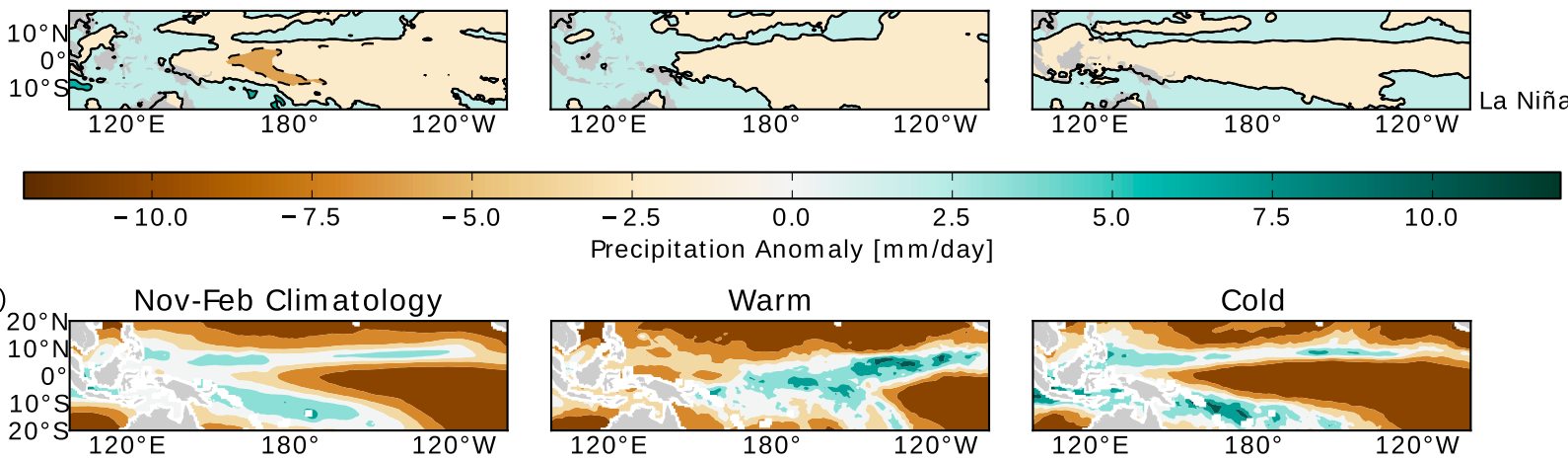

$-2.5$

Precipitation Anomaly [ $\mathrm{mm} / \mathrm{day}$ ]

(b)
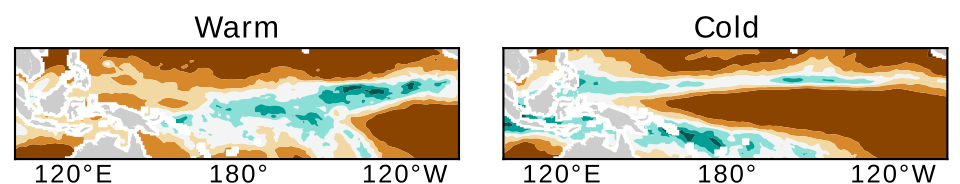

0.0

1.5

3.0

4.5

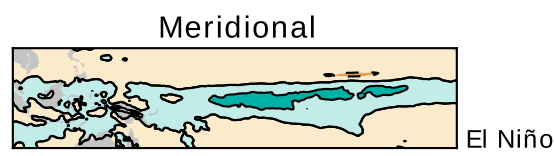

FIG. 5. (a) November-February precipitation anomaly $\left(\mathrm{mm} \mathrm{day}^{-1}\right)$ at left decomposed into zonal at center and meridional at right redistributions for El Niño on top and La Niña on bottom in MERRA. The contour interval is $4 \mathrm{~mm} \mathrm{day}^{-1}$. (b) Total precipitation for the climatology at left, during El Niño at center and La Niña at right in MERRA. An eastward (westward) and equatorward (poleward) movement of the ITCZ and SPCZ during El Niño (La Niña) is apparent.

model is almost entirely due to the zonal redistribution anomalies (Fig. 7).

It is informative to compare the zonal redistribution anomalies with and without concurrent meridional redistribution of precipitation, which show that the meridional redistribution plays an important role of limiting the zonal redistribution anomalies during La Niña (Fig. 7).
The zonal redistribution anomalies without concurrent meridional redistribution were calculated using Eq. (5). These nonconcurrent zonal redistribution anomalies can also be understood as the adjustment of the Walker circulation without any concurrent adjustment of the local Hadley cell. Under the situation when meridional redistribution is absent during La Niña (Fig. 7, right), there
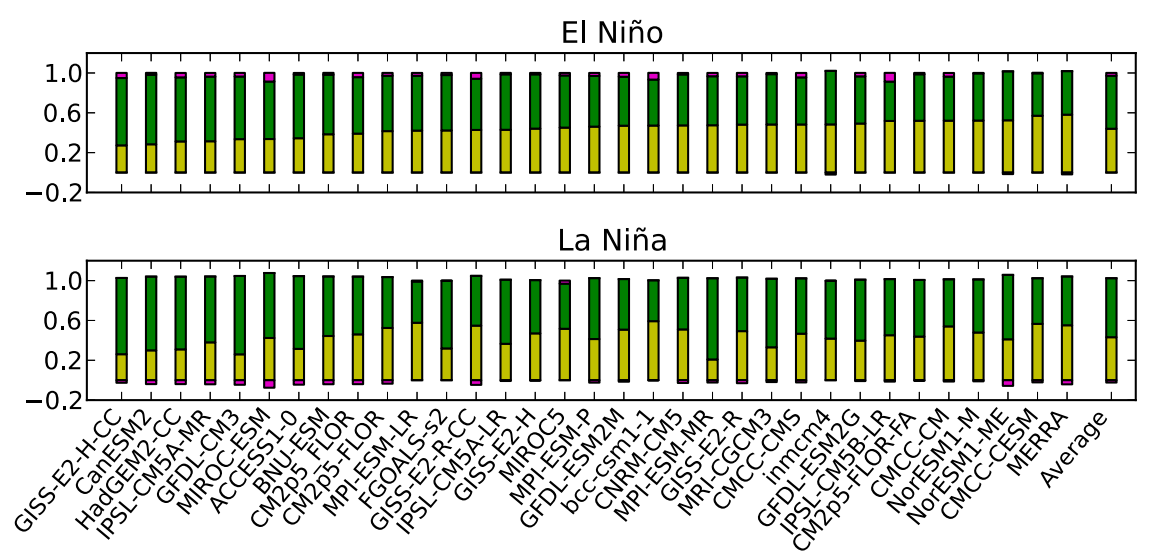

FIG. 6. Regression coefficients (dimensionless) with the total precipitation anomalies over the tropical Pacific $\left(20^{\circ} \mathrm{S}-20^{\circ} \mathrm{N}, 100^{\circ} \mathrm{E}-100^{\circ} \mathrm{W}\right)$ for the zonal redistribution of the climatological precipitation (yellow), the meridional redistribution of the climatological precipitation (green), and the residual (purple). Models are sorted by the zonal redistribution contribution during El Niño. 

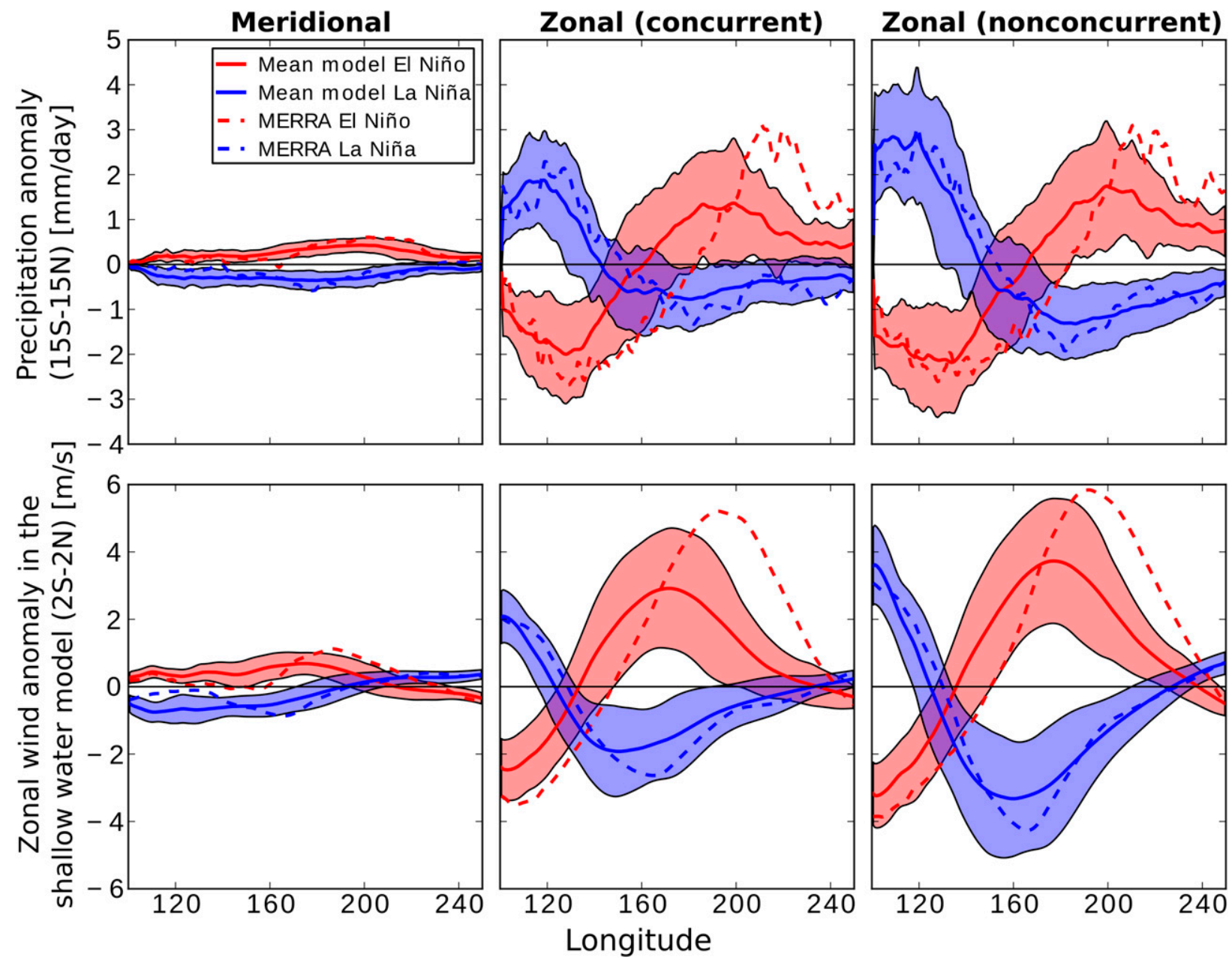

FIG. 7. (top) Precipitation anomaly ( $\mathrm{mm} \mathrm{day}^{-1}$ ) response to ENSO and (bottom) the corresponding zonal wind anomalies response to the heating anomalies in the shallow water model. Precipitation anomalies are averaged from $15^{\circ} \mathrm{S}$ to $15^{\circ} \mathrm{N}$, whereas wind anomalies are averaged from $2^{\circ} \mathrm{S}$ to $2^{\circ} \mathrm{N}$. (left) The meridional redistribution precipitation anomaly. (center) The zonal redistribution precipitation anomaly. (right) The pure zonal redistribution anomalies computed when the meridional redistribution anomalies are absent. Solid lines refer to results for the CMIP5 models and the dashed lines refer to that for the observations. Shading shows the standard deviations among the CMIP5 models.

is more precipitation to be displaced zonally, and therefore the zonal redistribution anomalies have a much stronger zonal dipole structure along the equator. Consequently the wind response to La Niña strengthens and the overall nonlinearity of the zonal wind response is reduced when meridional redistribution of precipitation is absent. Figure 8 shows that when the meridional redistribution component is absent, the nonlinearity in the zonal wind response to the zonal redistribution precipitation anomalies reduces significantly (the median reduction of all models is $65 \%$ ). In other words, the meridional redistribution of precipitation, although not directly driving a large equatorial zonal wind response, indirectly contributes to a significant amount of the nonlinearity of the zonal wind response by limiting the possible zonal redistribution of precipitation during La Niña

\section{c. Contributions from the biases in climatological precipitation}

In the previous subsection it was shown that the meridional redistribution of precipitation limits the equatorial zonal wind response during La Niña by exhausting the climatological precipitation on the equator. This suggests that the climatological precipitation may provide a simplifying framework from which to interpret intermodel spread in the nonlinear zonal wind response. In this section we study the extent to which biases in the climatological precipitation can help us understand biases in the zonal wind response nonlinearity in the models. 


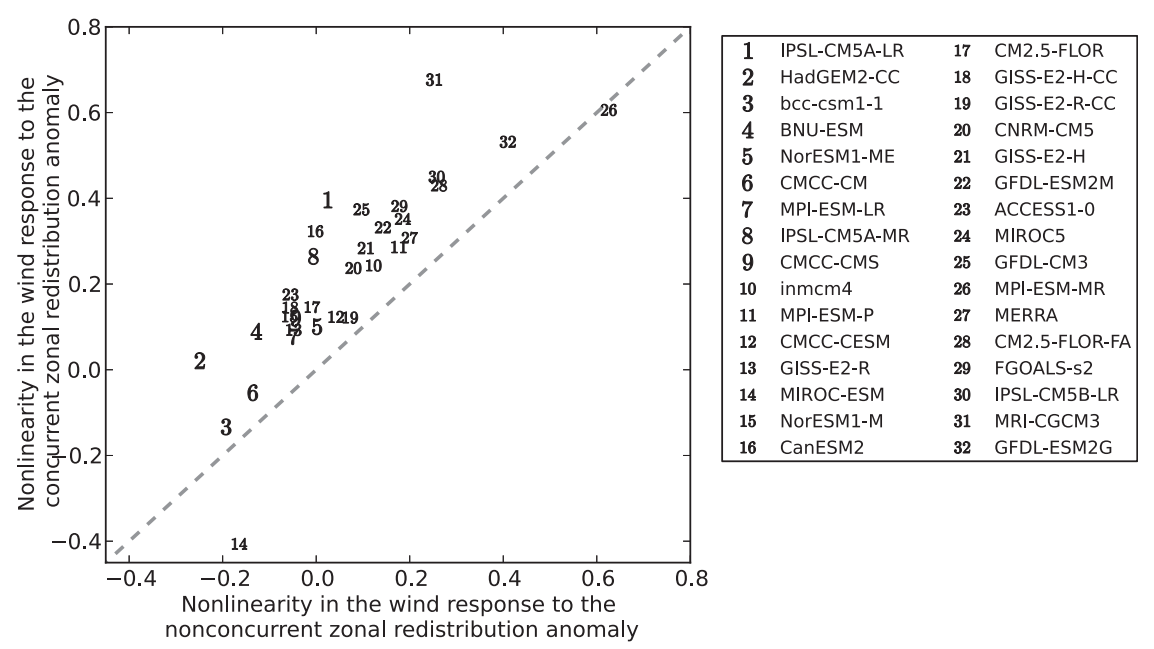

FIG. 8. The nonlinear wind response in the shallow water model forced by zonal redistribution precipitation anomalies with and without concurrent meridional redistribution anomalies. The straight line presents the reference for a one-to-one mapping. Points above this line indicate models whose nonlinear response is enhanced by the concurrent meridional redistribution of climatological precipitation.

\section{1) CM2.5-FLOR: FREE RUN VERSUS FLUX ADJUSTED}

The impact of climatological biases can be isolated by comparing the GFDL CM2.5-FLOR free-run simulation to another simulation where the surface ocean biases are corrected toward observations through flux adjustment (CM2.5-FLOR-FA; Vecchi et al. 2014; Jia et al. 2015). Since the two experiments have the same physics but differ only in their surface climatologies, and climatological precipitation is strongly sensitive to climatological SST, they provide us an opportunity to investigate the influence of climatological precipitation on the nonlinear zonal wind response to ENSO.

Both experiments simulate a tropical Pacific $\left(20^{\circ} \mathrm{S}-20^{\circ} \mathrm{N}\right.$, $100^{\circ} \mathrm{E}-100^{\circ} \mathrm{W}$ ) climatological precipitation (NovemberFebruary averaged) with spatial correlations above 0.9 relative to MERRA and GPCP (Fig. 9). The climatological precipitation over most of the equatorial central and eastern Pacific is drier in the simulation using the FLOR-FA version than in FLOR version of GFDL CM2.5 (Fig. 10). As a result, FLORFA is closer to MERRA and GPCP in terms of the area-mean precipitation. On the other hand, the SPCZ in FLOR-FA is more diagonal than that in FLOR. Yet this change in the spatial pattern is comparable to the difference between MERRA and GPCP, as MERRA also has a more diagonal SPCZ compared to GPCP.

With reference to MERRA, FLOR-FA is more similar in its linear equatorial zonal wind response to
El Niño than FLOR, whereas the errors in the zonal wind response to La Niña in FLOR-FA and FLOR are comparable (Fig. 1). The overall nonlinearity of zonal wind response in FLOR-FA is stronger than FLOR and is also closer to MERRA.

If the climatological precipitation from FLOR-FA is redistributed according to the spatial patterns of the FLOR's total precipitation during ENSO [i.e., swap the $P_{\text {clim }}$ for FLOR with that of FLOR-FA in Eqs. (1)-(4)], the resulting equatorial precipitation and the corresponding surface zonal wind anomalies simulated in the shallow water model (section 2 b) would be weaker (stronger) during La Niña (El Niño) compared to FLOR (Table 2). This is consistent with the previous section since a drier climatological precipitation further limits the negative precipitation anomalies during La Niña. Consequently, the nonlinearity in the zonal wind response is stronger when the climatological precipitation is taken from FLOR-FA.

However, if the wetter FLOR climatological precipitation is redistributed according to the FLOR-FA total precipitation spatial patterns, the equatorial zonal wind response becomes stronger (weaker) during $\mathrm{La}$ Niña (El Niño) compared to FLOR. In other words, the precipitation response to ENSO is changed when the surface climatology is flux adjusted so as to make the nonlinearity weaker. Nevertheless, the enhancement of the nonlinearity as a result of the drier FLOR-FA climatological precipitation is stronger (Table 2). As a result, by flux adjusting the ocean surface climatology toward the observations, the nonlinearity of the 


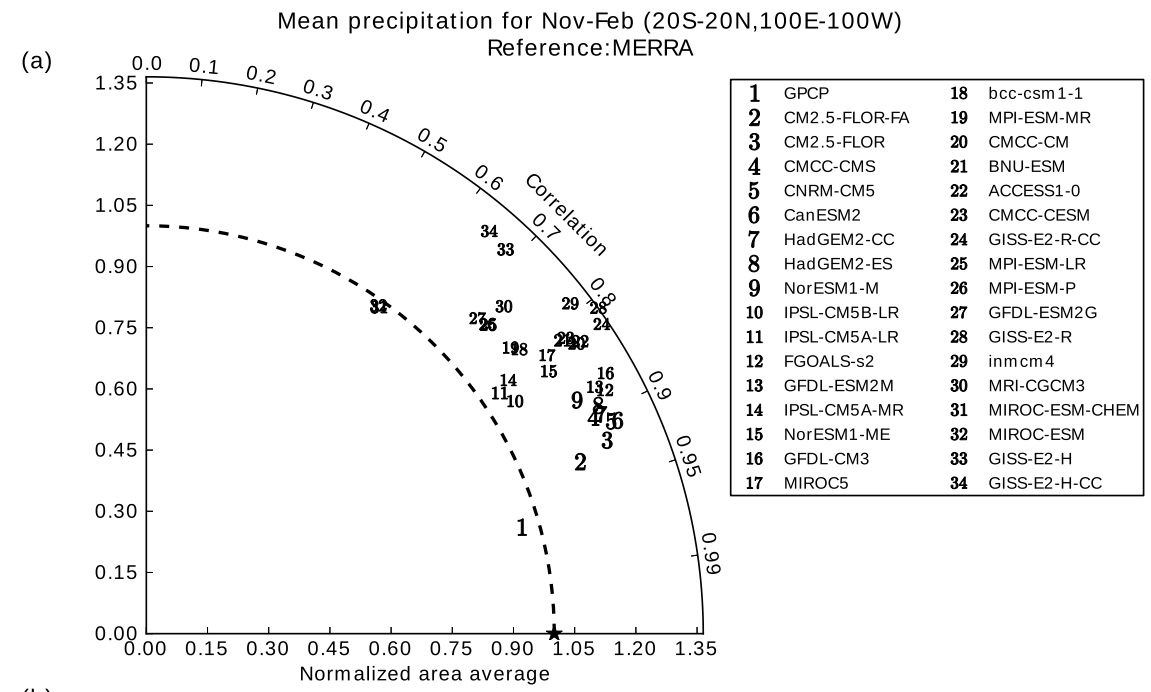

(b)

(c)

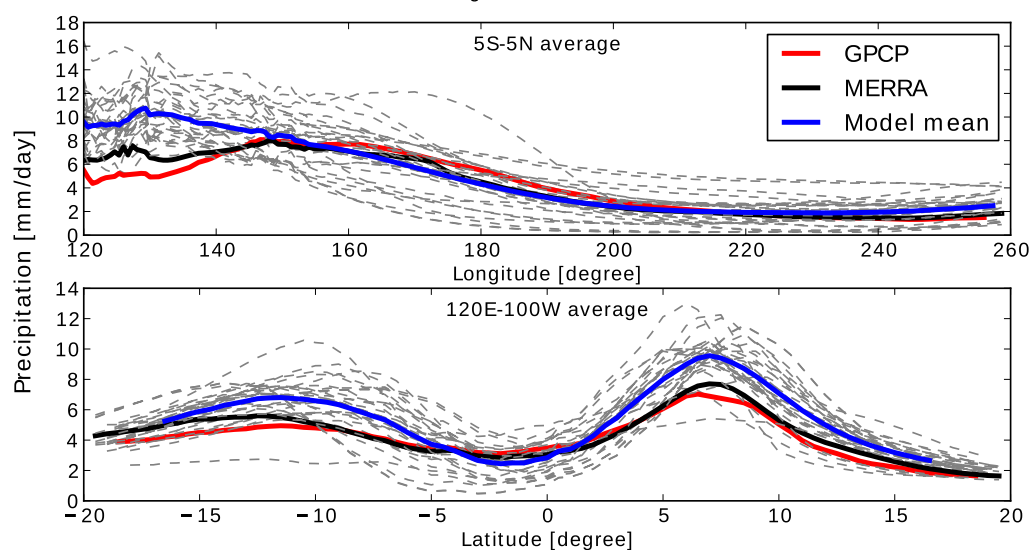

FIG. 9. Comparison of the tropical Pacific climatological precipitation $\left(20^{\circ} \mathrm{S}-20^{\circ} \mathrm{N}, 100^{\circ} \mathrm{E}-\right.$ $100^{\circ} \mathrm{W}$, ocean only, November-February averaged) for CMIP5 models, MERRA, and GPCP. (a) Taylor diagrams with reference to MERRA. Notice that the numbers associated with GPCP and the models are sorted by their distances from MERRA on the Taylor diagram. (b) Meridional average from $5^{\circ} \mathrm{S}$ to $5^{\circ} \mathrm{N}$. (c) Zonal average from $120^{\circ} \mathrm{E}$ to $100^{\circ} \mathrm{W}$. Gray dashed lines show the profiles for each model.

equatorial zonal wind response simulated by the FLOR is increased and becomes closer to observed.

\section{2) CMIP5: MODELS VERSUS OBSERVATIONS}

FLOR-FA shows an improvement in the linear and nonlinear zonal wind response to ENSO relative to FLOR, which arises, directly or indirectly, from improvements in climatological SST and rainfall. Here, we explore how the CMIP5 intermodel spread in the equatorial zonal wind response is associated with biases in their tropical Pacific climatologies and, in particular, their climatological precipitation fields.

Most CMIP5 models have a tropical Pacific mean climatological precipitation wetter than observed, with a spatial correlation ranging between 0.6 and 0.9 (Fig. 9). This wet bias is mostly due to the excess precipitation over the ITCZ, SPCZ, and the western Pacific warm pool regions. The multimodel mean precipitation has a weak dry bias near the equator, and the bias is comparable to the difference between GPCP and MERRA. However, the intermodel spread, especially over the dry cold tongue regions, is as large as $50 \%$ of the multimodel mean. As shown by Li and Xie (2014), when the precipitation field is normalized by the area mean for each model, the multimodel zonal-mean precipitation would align better in the ITCZ and SPCZ regions but nearly all models would have a normalized precipitation (i.e., spatial pattern only) that is too dry on the equator.

Models that have a cooler SST relative to the tropical Pacific mean and drier precipitation in the equatorial central Pacific climatologies tend to have a weaker equatorial zonal wind response during ENSO (Figs. 11a-c). 

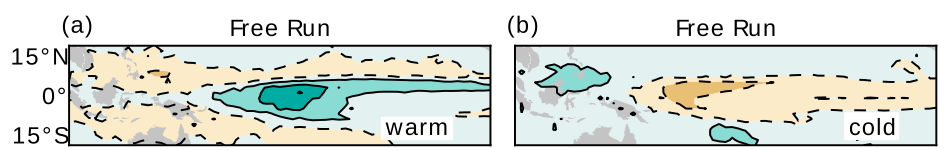

(d) Flux-adjusted

(e)

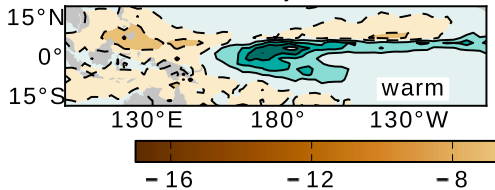

Flux-adjusted
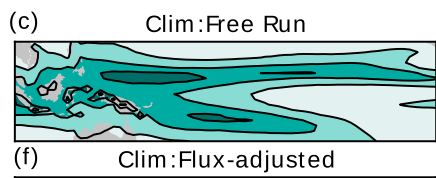

Clim:Flux-adjusted
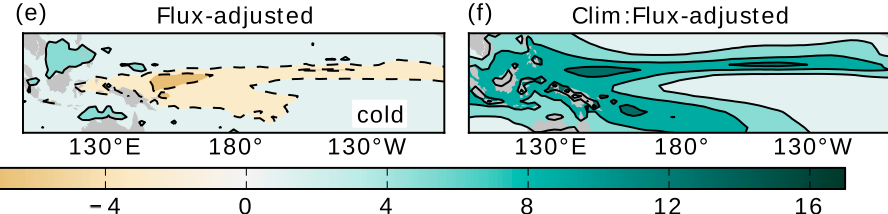

(g)
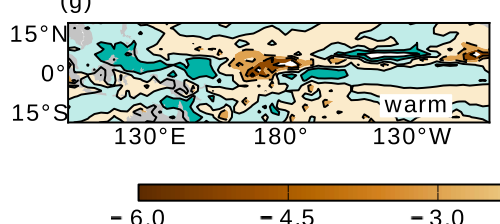

(h)

Free Run minus Flux-adjusted

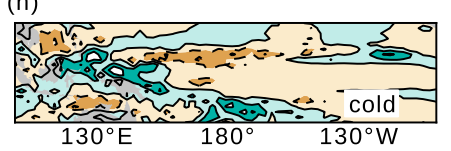

(i)

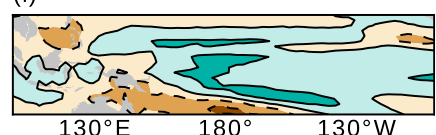

4.5

6.0

FIG. 10. Precipitation anomalies $\left(\mathrm{mm} \mathrm{day}^{-1}\right.$ ) averaged from November to February during (a),(d) El Niño and (b),(e) La Niña for the (top) CM2.5-FLOR and (middle) CM2.5-FLOR-FA. (right) The climatological precipitation for (c) CM2.5-FLOR and (f) CM2.5-FLOR-FA. (g)-(i) Differences (mm day ${ }^{-1}$ ) between (a),(b) and (d),(e), respectively. Contour intervals are 4 and $2 \mathrm{~mm} \mathrm{day}^{-1}$ in (a)-(f) and (g)-(i), respectively.

This shows that the climatological cold tongue bias and the location of the warm pool edge are important for the linear atmosphere-ocean coupling strength over the equatorial Pacific during ENSO.

The correlation between the climatological precipitation and the equatorial zonal wind response to ENSO described here is insensitive to whether or not the tropical Pacific mean precipitation of each model is removed or used to normalize the precipitation field (not shown). This insensitivity is likely because the intermodel spread in the tropical Pacific mean precipitation is relatively small compared to local differences.

In contrast, the correlation between the tropical climatological SST and the zonal wind response is smaller when the tropical Pacific mean SST is included (not shown). This is consistent with Sobel et al. (2002), Johnson and Xie (2010), and Xie et al. (2010) since the tropical deep convection is controlled not only by the local SST but also the difference between the local SST and the tropical mean SST, as well as the meridional temperature gradient.
The nonlinearity in the zonal wind response has virtually no linear correlation with the bias in the climatological precipitation in the equatorial central Pacific (Fig. 11d). This is because, while a dry bias in the equatorial central Pacific (associated with the erroneous zonal extent of the cold tongue in some of the models; Brown et al. 2014) causes a weaker La Niña wind response by limiting the possible negative precipitation anomalies, the El Niño zonal wind response is also often weakened in the dry models. Therefore, although there is a strong linear relationship between the linear zonal wind response and the climatological precipitation biases, the bias in the nonlinearity cannot be determined directly from the bias in the climatological precipitation.

\section{Conclusions}

Observations and the CMIP5 models have shown stronger equatorial zonal wind response to El Niño than to La Niña. The observed nonlinearity in the zonal wind

TABLE 2. Magnitudes of the maximum zonal wind anomalies in the shallow water model for different precipitation anomalies either from a single model or by redistributing another model's climatological precipitation $P_{\text {clim }}$ to one model's total precipitation pattern $P_{\text {total }}$ during ENSO. The $\Delta r_{c}$ denotes the change in the nonlinearity from changing the climatological precipitation. The $\Delta r_{t}$ denotes the change in the nonlinearity from changing the total precipitation pattern. Changes are with reference to the free-run experiment (GFDL CM2.5FLOR; top row).

\begin{tabular}{llccc}
\hline \hline \multicolumn{1}{c}{ Climatology } & \multicolumn{1}{c}{$P_{\text {total }}$} & El Niño $\left(\mathrm{m} \mathrm{s}^{-1}\right)$ & La Niña $\left(\mathrm{m} \mathrm{s}^{-1}\right)$ & $\Delta r_{c}$ \\
\hline CM2.5-FLOR & CM2.5-FLOR & 4.64 & -3.54 & - \\
CM2.5-FLOR & CM2.5-FLOR-FA & 3.47 & -4.97 & - \\
CM2.5-FLOR-FA & CM2.5-FLOR & 7.14 & -1.32 & -0.31 \\
CM2.5-FLOR-FA & CM2.5-FLOR-FA & 5.97 & -2.70 & - \\
MERRA & MERRA & 5.58 & -2.93 & - \\
\hline
\end{tabular}




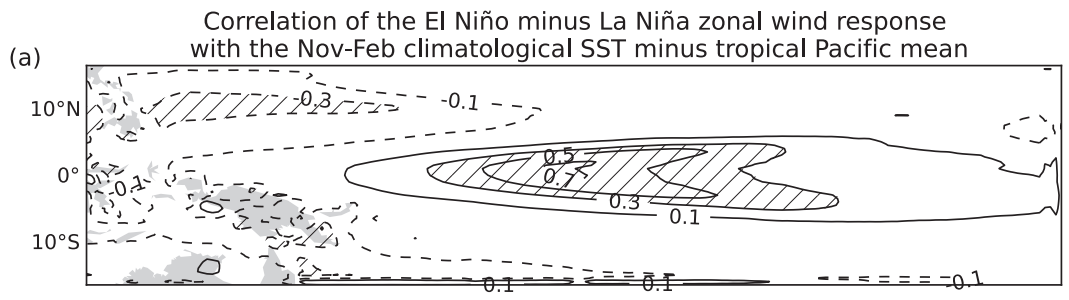

Correlation of the El Niño minus La Niña zonal wind response

(b) with the Nov-Feb climatological precipitation

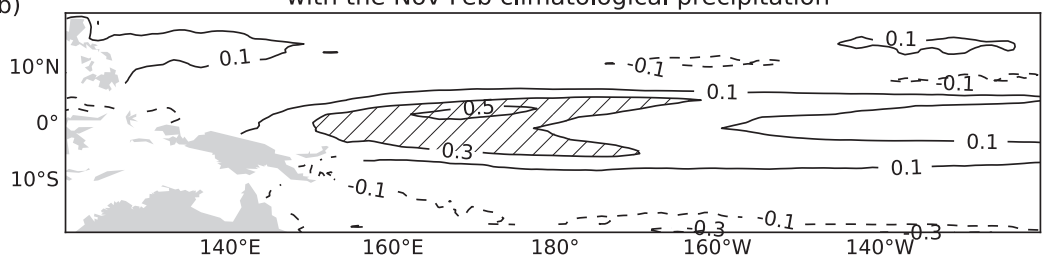

(c)

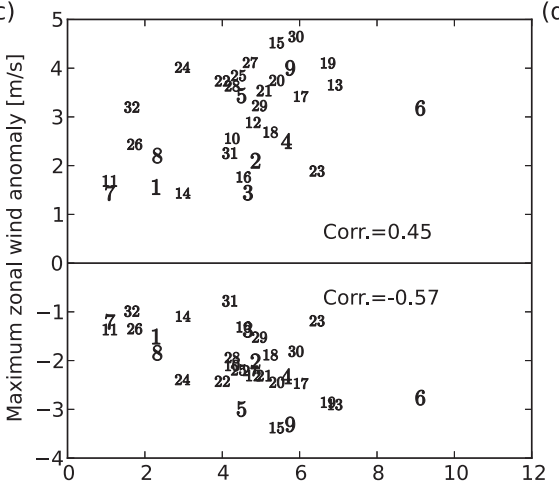

(d)

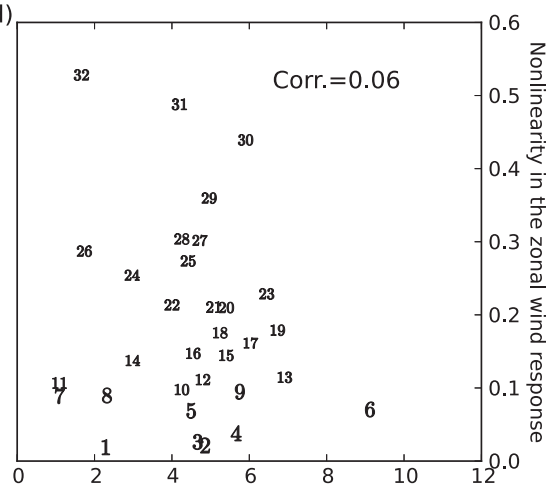

Climatological precipitation [ $\mathrm{mm} /$ day] (Nov-Feb, 5S-5N, 160E-160W)

\begin{tabular}{|llclllll|}
\hline 1 & IPSL-CM5A-LR & 9 & CMCC-CMS & 17 & CM2.5-FLOR & 25 & GFDL-CM3 \\
2 & HadGEM2-CC & 10 & inmcm4 & 18 & GISS-E2-H-CC & 26 & MPI-ESM-MR \\
3 & bCc-CSm1-1 & 11 & MPI-ESM-P & 19 & GISS-E2-R-CC & 27 & MERRA \\
4 & BNU-ESM & 12 & CMCC-CESM & 20 & CNRM-CM5 & 28 & CM2.5-FLOR-FA \\
5 & NorESM1-ME & 13 & GISS-E2-R & 21 & GISS-E2-H & 29 & FGOALS-S2 \\
6 & CMCC-CM & 14 & MIROC-ESM & 22 & GFDL-ESM2M & 30 & IPSL-CM5B-LR \\
7 & MPI-ESM-LR & 15 & NorESM1-M & 23 & ACCESS1-0 & 31 & MRI-CGCM3 \\
8 & IPSL-CM5A-MR & 16 & CanESM2 & 24 & MIROC5 & 32 & GFDL-ESM2G \\
\hline
\end{tabular}

FIG. 11. Relationship between the equatorial zonal wind anomalies and the NovemberFebruary climatological precipitation across the CMIP5 models. (a) The differences of the El Niño and La Niña maximum zonal wind response for the CMIP5 models are correlated with the models' climatological SST (with the tropical Pacific mean for each model removed) at every grid point. Regions with statistical significance above $95 \%$ are hatched. (b) As in (a), but for the climatological precipitation. (c) Scatterplot of the maximum (minimum) equatorial zonal wind anomalies during El Niño (La Niña) with the climatological precipitation averaged within $5^{\circ} \mathrm{S}-$ $5^{\circ} \mathrm{N}, 160^{\circ} \mathrm{E}-160^{\circ} \mathrm{W}$ for the CMIP5 model and MERRA. (d) Scatterplot of the nonlinearity in the zonal wind response [Eq. (6)] with the said climatological precipitation average.

response can be reproduced fairly well by driving an atmospheric shallow water model with the observed precipitation anomalies as the heating source. The varying degree of the wind nonlinearity in the CMIP5 models is also reproduced using the models' precipitation anomalies in the shallow water model. We therefore conclude that the nonlinearity in the zonal wind response is largely driven by the nonlinear response of the precipitation, which is a positive definite quantity.
More than $90 \%$ of the precipitation anomalies during ENSO are due to the redistribution of the tropical Pacific climatological precipitation, with little change to the overall mean precipitation. We derived a routine to decompose the precipitation anomalies into three components: zonal redistribution, meridional redistribution, and a residual component which tends to be small. These components are computed such that the zonal (meridional) redistribution component has zero zonal (meridional) 
mean at all latitudes (longitudes) within the tropical Pacific region (Figs. 5 and 6).

Based on experiments with a shallow water model, we conclude that although the zonal and meridional redistribution components contribute comparably to the equatorial precipitation anomalies, the zonal redistribution component is responsible for most of the equatorial zonal wind response (Fig. 7). However, the meridional redistribution component during La Niña, associated with the poleward shift of the ITCZ/SPCZ (Trenberth 1976; Folland et al. 2002), enhances the nonlinearity in the zonal wind response substantially by reducing the climatological precipitation on the equator, thereby reducing the zonal redistribution and the zonal wind response to La Niña (section 3b). This result highlights the role of climatological precipitation in limiting the zonal wind response to La Niña. On the other hand, the meridional shift during El Niño has little effect on the precipitation and the wind response.

By comparing the free-run and the flux-adjusted experiments of the GFDL CM2.5-FLOR model, we found that both the linear and the nonlinear zonal wind response to ENSO are improved by flux correcting the surface ocean climatologies toward the observed. And among the CMIP5 models, the equatorial zonal wind response to ENSO is also shown to be associated with the equatorial central Pacific climatological precipitation and SST (Fig. 11). Previous studies analyzing the CMIP3 models have also indicated relationships between the models' biases in their climatological precipitation and equatorial zonal wind response to ENSO (Capotondi et al. 2006; Lengaigne and Vecchi 2010; Ohba and Ueda 2009). Together, these findings imply that the equatorial atmosphere-ocean coupling strength may change under a different climate scenario if there are changes in the climatological SST and precipitation near the edge of the cold tongue.

For the CMIP5 preindustrial control experiments, the linear zonal wind response to ENSO has a significant linear dependence on the equatorial central Pacific climatological precipitation and SST (i.e., near the edge of cold tongue), and little linear dependence of the nonlinear zonal wind response on the climatological precipitation is found. Therefore, we speculate that the intermodel differences in the nonlinear atmospheric response to ENSO are likely due to the different representations of the atmospheric processes rather than the different ocean surface climatologies in the models. But it may be possible to improve model representations of the linear wind response to ENSO by correcting ocean surface biases.

Acknowledgments. The authors thank the three anonymous reviewers for their comments and suggestions. The
Modern-Era Retrospective Analysis for Research and Applications (MERRA) reanalysis data are provided by the Global Modeling and Assimilation Office (GMAO) and the Goddard Earth Sciences Data and Information Services Center (GES DISC). The Global Precipitation Climatology Project, version 2.2, (GPCP) data are produced by an international set of scientists and organizations. Satellite data were collected by NOAA, the Japan Meteorological Agency, the European Space Agency, and EUMETSAT. The authors are grateful for all that have contributed to the preparation and dissemination of the datasets. This report was prepared by $\mathrm{KC}$ under Award NA08OAR4320752 from the National Oceanic and Atmospheric Administration and U.S. Department of Commerce. The statements, findings, conclusions, and recommendations are those of the authors and do not necessarily reflect the views of the National Oceanic and Atmospheric Administration or the U.S. Department of Commerce.

\section{APPENDIX}

\section{Uniqueness of the Decomposition Solution}

This appendix proves the uniqueness of the solution given by the decomposition method described in section $2 \mathrm{c}$. The solution is unique because of the requirement that the solution should not depend on the order of the zonal and meridional redistribution (i.e., the two redistributions occur simultaneously). Unless there is a reason to believe that the Walker circulation adjusts before the local Hadley cell does (or vice versa), the simultaneity is the best assumption that one could make. We will show how the simultaneity leads to a unique solution.

As the residual component can be uniquely defined by the difference between the total precipitation field during El Niño (or La Niña) and the same field normalized by the tropical mean climatological precipitation, for now we may ignore the residual component (i.e., any basinwide intensification or reduction of precipitation) and focus on the pure spatial (two dimensional) redistribution of precipitation in the tropical Pacific.

With that, we let

$$
P^{\prime}=P_{x}^{\prime}+P_{y}^{\prime},
$$

where $P^{\prime}$ represents the total precipitation anomalies with zero area mean, $P_{x}^{\prime}$ is the precipitation anomaly resulting from the zonal redistribution, and $P_{y}^{\prime}$ is the precipitation anomaly resulting from the meridional redistribution. By definition, the zonal mean of $P_{x}^{\prime}$ is zero, and the meridional mean of $P_{y}^{\prime}$ is zero. We shall prove that this is a unique decomposition under the aforementioned assumptions. 
(a)

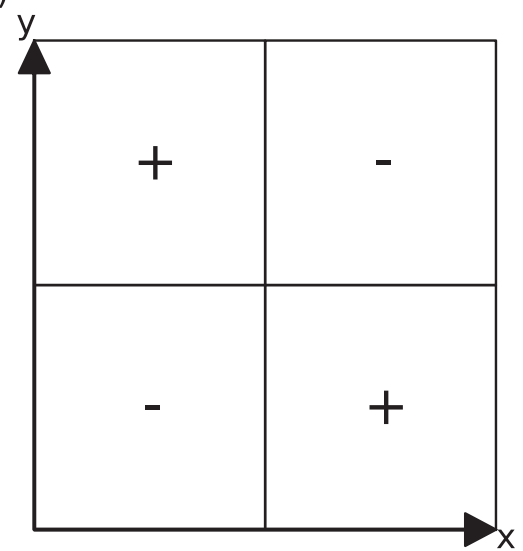

(b)

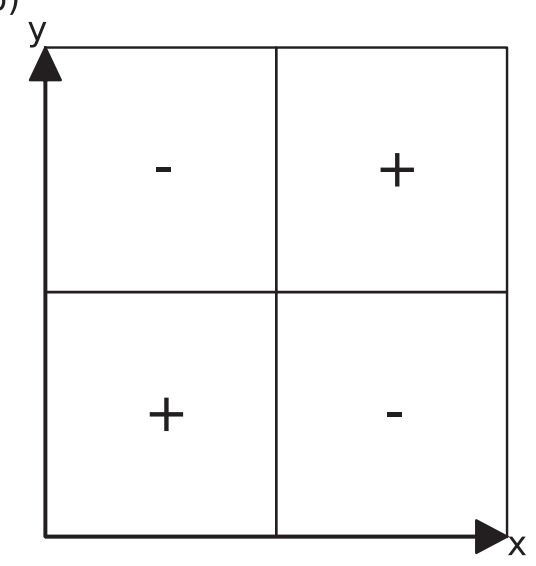

FIG. A1. Two-dimensional quadrupole structures.

An alternative solution for the decomposition would be

$$
\begin{aligned}
P_{x, 1}^{\prime} & =P_{x}^{\prime}+P_{1} \text { and } \\
P_{y, 1}^{\prime} & =P_{y}^{\prime}-P_{1}, \text { so that } \\
P^{\prime} & =P_{x, 1}^{\prime}+P_{y, 1}^{\prime} .
\end{aligned}
$$

(a)
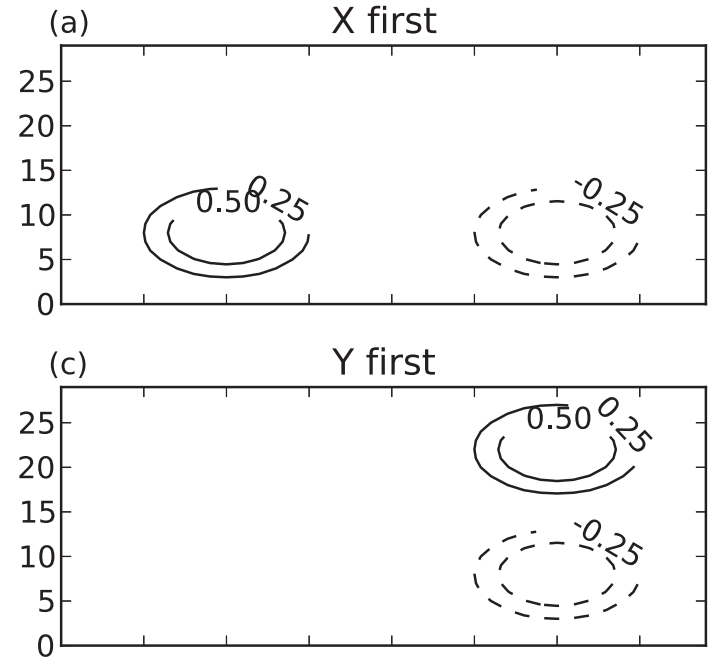

(e)

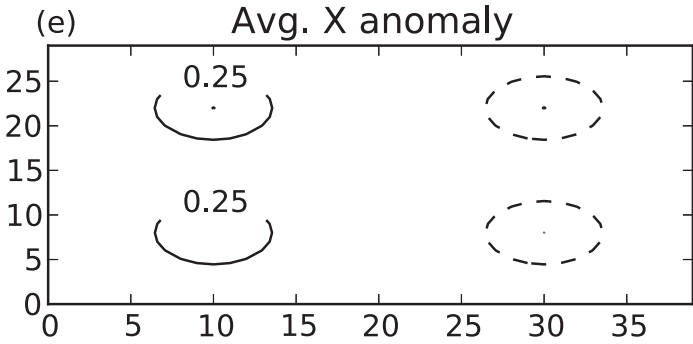

To satisfy all the above statements, $P_{1}$ has zero zonal mean and zero meridional mean. Therefore, $P_{1}$ is either zero everywhere or has a structure of a quadrupole or higher-order multipoles. We will continue the proof with the quadrupole solutions, which can be easily generalized to higher-order multipoles. There (b)
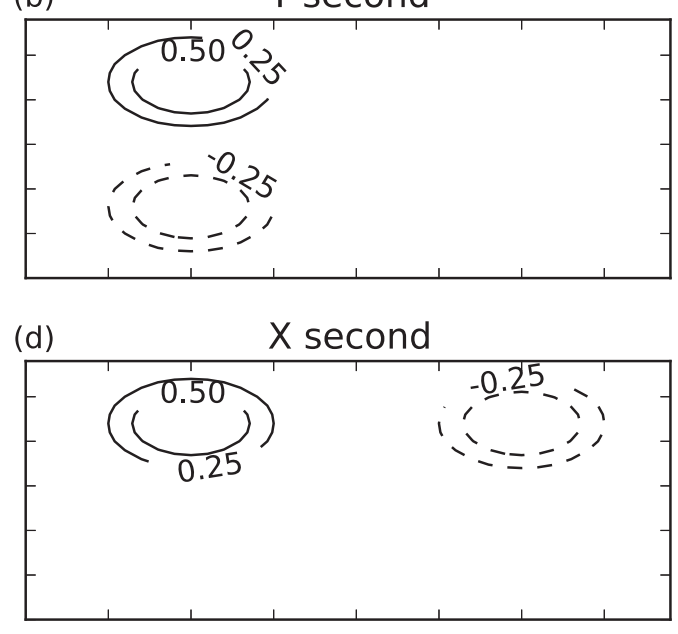

(f)

Avg. Y anomaly

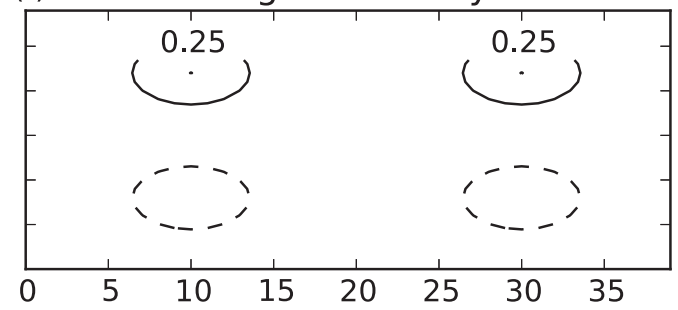

FIG. A2. Decomposition of the anomalies resulted from moving some scalar quantities from the bottom right corner to the top left corner. (a) Zonal redistribution anomaly is assumed to take place before (b) the meridional redistribution anomaly. (c) The meridional redistribution anomaly happens before (d) the zonal redistribution anomaly. (e) The average of (a) and (d). (f) The averaged of (b) and (c). The iterative method described in the text gives the same answers as (e) and (f), exact to the order at which the algorithm is designed to converge. 
are two quadrupoles that $P_{1}$ could be (as shown in Fig. A1).

Without loss of generality, let $P_{1}$ take the structure of Fig. A1a; that is, add Fig. A1a to $P_{x}^{\prime}$ and add an equal magnitude of Fig. A1b to $P_{y}^{\prime}$. This forms a proposed alternative solution. But this solution violates our assumption that the zonal and meridional redistributions occur simultaneously.

What the additional $P_{1}$ implies is a counterclockwise movement of a block of precipitation that eventually moves back to where it was and causes no overall anomaly anywhere. This also implies a preferred order of redistribution. In other words, when there is no preference for the zonal redistribution to occur prior to the meridional redistribution, another choice of $P_{1}$ (i.e., a clockwise movement) should exist if the counterclockwise solution existed. These two choices of $P_{1}$ cancel each other. Therefore, there is no alternative solution to $P^{\prime}=P_{x}^{\prime}+P_{y}^{\prime}$. Q.E.D.

In the current implementation, $P_{1}$ is eliminated by small-step iterations between the zonal redistribution and the meridional redistribution operations. An alternative implementation would be to average two pairs of redistribution anomalies: the first set assumes that all of the zonal redistribution takes place before the meridional redistribution; the second set assumes the opposite. Then the average of the two sets of $\left(P_{x}^{\prime}, P_{y}^{\prime}\right)$ would have no preference for the order of redistribution (i.e., the clockwise and counterclockwise movements are averaged out). This implementation is illustrated in Fig. A2.

The iterative method (used in the main body of this paper) and the averaging method give answers that are the same, exact to the order at which the first method is designed to converge ( $1 \%$ of the anomalies for the experiments presented). In retrospect, the second method may be better because there is no need for an iteration and a choice when the iteration converges. But the first method gives intermediate steps for animating how the redistribution occurs progressively.

\section{REFERENCES}

Adler, R. F., and Coauthors, 2003: The Version-2 Global Precipitation Climatology Project (GPCP) monthly precipitation analysis (1979-present). J. Hydrometeor., 4, 1147-1167, doi:10.1175/1525-7541(2003)004<1147:TVGPCP>2.0.CO;2.

Balaji, V., 1998: Parallelization of a spectral atmospheric GCM. Proc. Second Int. Workshop on Software Engineering and Code Design in Parallel Meteorological and Oceanographic Applications, Scottsdale, AZ, National Aeronautics and Space Administration, NASA/GSFC/CP-206860.

Brown, J. N., C. Langlais, and C. Maes, 2014: Zonal structure and variability of the western Pacific dynamic warm pool edge in CMIP5. Climate Dyn., 42, 3061-3076, doi:10.1007/ s00382-013-1931-5.
Capotondi, A., A. Wittenberg, and S. Masina, 2006: Spatial and temporal structure of tropical Pacific interannual variability in 20th century coupled simulations. Ocean Modell., 15, 274-298, doi:10.1016/j.ocemod.2006.02.004.

Chiang, J. C. H., S. E. Zebiak, and M. A. Cane, 2001: Relative roles of elevated heating and surface temperature gradients in driving anomalous surface winds over tropical oceans. J. Atmos. Sci., 58, 1371-1394, doi:10.1175/1520-0469(2001)058<1371: RROEHA $>2.0 . \mathrm{CO} ; 2$.

Choi, K.-Y., G. A. Vecchi, and A. T. Wittenberg, 2013: ENSO transition, duration, and amplitude asymmetries: Role of the nonlinear wind stress coupling in a conceptual model. J. Climate, 26, 9462-9476, doi:10.1175/JCLI-D-13-00045.1.

Chung, C. T. Y., and S. B. Power, 2014: Precipitation response to La Niña and global warming in the Indo-Pacific. Climate Dyn., 43, 3293-3307, doi:10.1007/s00382-014-2105-9.

,-- J. M. Arblaster, H. A. Rashid, and G. L. Roff, 2013: Nonlinear precipitation response to $\mathrm{El}$ Niño and global warming in the Indo-Pacific. Climate Dyn., 42, 1837-1856, doi:10.1007/s00382-013-1892-8.

Delworth, T. L., and Coauthors, 2006: GFDL's CM2 global coupled climate models. Part I: Formulation and simulation characteristics. J. Climate, 19, 643-674, doi:10.1175/JCLI3629.1.

_ , and Coauthors, 2012: Simulated climate and climate change in the GFDL CM2.5 high-resolution coupled climate model. J. Climate, 25, 2755-2781, doi:10.1175/JCLI-D-11-00316.1.

Dommenget, D., T. Bayr, and C. Frauen, 2013: Analysis of the nonlinearity in the pattern and time evolution of El Niño Southern Oscillation. Climate Dyn., 40, 2825-2847, doi:10.1007/ s00382-012-1475-0.

Folland, C. K., J. A. Renwick, M. J. Salinger, and A. B. Mullan, 2002: Relative influences of the interdecadal Pacific oscillation and ENSO on the South Pacific convergence zone. Geophys. Res. Lett., 29, 1643, doi:10.1029/2001GL014201.

Frauen, C., and D. Dommenget, 2010: El Niño and La Niña amplitude asymmetry caused by atmospheric feedbacks. Geophys. Res. Lett., 37, L18801, doi:10.1029/2010GL044444.

Gill, A., 1980: Some simple solutions for heat-induced tropical circulation. Quart. J. Roy. Meteor. Soc., 106, 447-462, doi:10.1002/qj.49710644905.

— , and A. Clarke, 1974: Wind-induced upwelling, coastal currents and sea-level changes. Deep-Sea Res. Oceanogr. Abstr., 21, 325-345, doi:10.1016/0011-7471(74)90038-2.

Haddad, Z. S., J. P. Meagher, R. F. Adler, E. A. Smith, E. Im, and S. L. Durden, 2004: Global variability of precipitation according to the Tropical Rainfall Measuring Mission. J. Geophys. Res., 109, D17103, doi:10.1029/2004JD004607.

Harrison, D. E., and G. A. Vecchi, 1999: On the termination of El Niño. Geophys. Res. Lett., 26, 1593-1596, doi:10.1029/1999GL900316.

Hoerling, M. P., A. Kumar, and M. Zhong, 1997: El Niño, La Niña, and the nonlinearity of their teleconnections. J. Climate, 10, 1769-1786, doi:10.1175/1520-0442(1997)010<1769: ENOLNA $>2.0 . \mathrm{CO} ; 2$.

,-- , and T. Xu, 2001: Robustness of the nonlinear climate response to ENSO's extreme phases. J. Climate, 14, 1277-1293, doi:10.1175/1520-0442(2001)014<1277:ROTNCR>2.0.CO;2.

Jia, L., and Coauthors, 2015: Improved seasonal prediction of temperature and precipitation over land in a high-resolution GFDL climate model. J. Climate, 28, 2044-2062, doi:10.1175/ JCLI-D-14-00112.1.

Johnson, N. C., and S.-P. Xie, 2010: Changes in the sea surface temperature threshold for tropical convection. Nat. Geosci., $\mathbf{3}$, 842-845, doi:10.1038/ngeo1008. 
Kang, I.-S., and J.-S. Kug, 2002: El Niño and La Niña sea surface temperature anomalies: Asymmetry characteristics associated with their wind stress anomalies. J. Geophys. Res., 107, 4372, doi:10.1029/2001JD000393.

Kessler, W. S., 2002: Is ENSO a cycle or a series of events? Geophys. Res. Lett., 29, 2125, doi:10.1029/2002GL015924.

Larkin, N. K., and D. E. Harrison, 2002: ENSO warm (El Niño) and cold (La Niña) event life cycles: Ocean surface anomaly patterns, their symmetries, asymmetries, and implications. J. Climate, 15, 1118-1140, doi:10.1175/1520-0442(2002)015<1118: EWENOA $>2.0 . \mathrm{CO} ; 2$

Lengaigne, M., and G. A. Vecchi, 2010: Contrasting the termination of moderate and extreme El Niño events in coupled general circulation models. Climate Dyn., 35, 299-313, doi:10.1007/s00382-009-0562-3.

Li, G., and S.-P. Xie, 2014: Tropical biases in CMIP5 multimodel ensemble: The excessive equatorial pacific cold tongue and double ITCZ problems. J. Climate, 27, 1765-1780, doi:10.1175/ JCLI-D-13-00337.1.

Lindzen, R. S., and S. Nigam, 1987: On the role of sea surface temperature gradients in forcing low-level winds and convergence in the tropics. J. Atmos. Sci., 44, 2418-2436, doi:10.1175/ 1520-0469(1987)044<2418:OTROSS >2.0.CO;2.

Matsuno, T., 1966: Quasi-geostrophic motions in the equatorial area. J. Meteor. Soc. Japan Ser. II, 44, 25-43.

McGregor, S., A. Timmermann, N. Schneider, M. F. Stuecker, and M. H. England, 2012: The effect of the South Pacific convergence zone on the termination of El Niño events and the meridional asymmetry of ENSO. J. Climate, 25, 5566-5586, doi:10.1175/JCLI-D-11-00332.1.

Neelin, J. D., 1989: On the interpretation of the Gill model. J. Atmos. Sci., 46, 2466-2468, doi:10.1175/1520-0469(1989)046<2466: OTIOTG $>2.0 . \mathrm{CO} ; 2$.

Ohba, M., and H. Ueda, 2009: Role of nonlinear atmospheric response to SST on the asymmetric transition process of ENSO. J. Climate, 22, 177-192, doi:10.1175/2008JCLI2334.1.
Okumura, Y. M., and C. Deser, 2010: Asymmetry in the duration of El Niño and La Niña. J. Climate, 23, 5826-5843, doi:10.1175/ 2010JCLI3592.1.

Philip, S., and G. J. van Oldenborgh, 2009: Significant atmospheric nonlinearities in the ENSO cycle. J. Climate, 22, 4014-4028, doi:10.1175/2009JCLI2716.1.

Rienecker, M. M., and Coauthors, 2011: MERRA: NASA's Modern-Era Retrospective Analysis for Research and Applications. J. Climate, 24, 3624-3648, doi:10.1175/ JCLI-D-11-00015.1.

Sobel, A. H., I. M. Held, and C. S. Bretherton, 2002: The ENSO signal in tropical tropospheric temperature. J. Climate, 15, 2702-2706, doi:10.1175/1520-0442(2002)015<2702: TESITT $>2.0 . \mathrm{CO} ; 2$.

Taylor, K. E., R. J. Stouffer, and G. A. Meehl, 2012: An overview of CMIP5 and the experiment design. Bull. Amer. Meteor. Soc., 93, 485-498, doi:10.1175/BAMS-D-11-00094.1.

Trenberth, K. E., 1976: Spatial and temporal variations of the Southern Oscillation. Quart. J. Roy. Meteor. Soc., 102, 639653, doi:10.1002/qj.49710243310.

Vecchi, G. A., 2006: The termination of the 1997-98 El Niño. Part II: Mechanisms of atmospheric change. J. Climate, 19, 26472664, doi:10.1175/JCLI3780.1

— , and Coauthors, 2014: On the seasonal forecasting of regional tropical cyclone activity. J. Climate, 27, 7994-8016, doi:10.1175/ JCLI-D-14-00158.1.

Wu, Z., E. S. Sarachik, and D. S. Battisti, 2001: Thermally driven tropical circulations under Rayleigh friction and Newtonian cooling: Analytic solutions. J. Atmos. Sci., 58, 724-741, doi:10.1175/1520-0469(2001)058<0724:TDTCUR > 2.0.CO;2.

Xie, S.-P., C. Deser, G. A. Vecchi, J. Ma, H. Teng, and A. T. Wittenberg, 2010: Global warming pattern formation: Sea surface temperature and rainfall. J. Climate, 23, 966-986, doi:10.1175/2009JCLI3329.1.

Zhang, T., and D.-Z. Sun, 2014: ENSO asymmetry in CMIP5 models. J. Climate, 27, 4070-4093, doi:10.1175/JCLI-D-13-00454.1. 